University of Nebraska - Lincoln

DigitalCommons@University of Nebraska - Lincoln

Faculty Publications: Department of

Entomology

Entomology, Department of

2008

Invasion of Europe by the western corn rootworm, Diabrotica

virgifera virgifera: multiple transatlantic introductions with various

reductions of genetic diversity

M. Ciosi

INRA-UNSA-CNRS, Sophia Antipolis, France

Nicholas Miller

University of Nebraska-Lincoln, nmiller11@iit.edu

R. Giordano

Illinois Natural History Survey

A. Estoup

INRA, UMR CBGP, INRA/IRD/Cirad/Montpellier SupAgro

T. Guillemaud

INRA-UNSA-CNRS, Sophia Antipolis, France

See next page for additional authors

Follow this and additional works at: https://digitalcommons.unl.edu/entomologyfacpub

Part of the Entomology Commons

Ciosi, M.; Miller, Nicholas; Giordano, R.; Estoup, A.; Guillemaud, T.; and Kim, S., "Invasion of Europe by the western corn rootworm, Diabrotica virgifera virgifera: multiple transatlantic introductions with various reductions of genetic diversity" (2008). Faculty Publications: Department of Entomology. 249.

https://digitalcommons.unl.edu/entomologyfacpub/249

This Article is brought to you for free and open access by the Entomology, Department of at DigitalCommons@University of Nebraska - Lincoln. It has been accepted for inclusion in Faculty Publications: Department of Entomology by an authorized administrator of DigitalCommons@University of Nebraska - Lincoln. 
Authors

M. Ciosi, Nicholas Miller, R. Giordano, A. Estoup, T. Guillemaud, and S. Kim

This article is available at DigitalCommons@University of Nebraska - Lincoln: https://digitalcommons.unl.edu/ entomologyfacpub/249 


\title{
Invasion of Europe by the western corn rootworm, Diabrotica virgifera virgifera: multiple transatlantic introductions with various reductions of genetic diversity
}

\author{
M. CIOSI,$*$ N. J. MILlER,, K. S. KIM,+R. GIORDANO, $\ddagger$ A. ESTOUP§ and T. GUILLEMAUD* \\ *Equipe 'Biologie des Populations en Interaction', UMR 1301 I.B.S.V. INRA-UNSA-CNRS, 400 Route des Chappes, BP 167-06903 \\ Sophia Antipolis cedex, France, +USDA-ARS, CICGRU, Genetics Laboratory, Iowa State University, Ames, IA 50011, USA, †Division \\ of Biodiversity and Ecological Entomology, Illinois Natural History Survey, Champaign, IL 61820, USA, §INRA, UMR CBGP (INRA/ \\ IRD/Cirad/Montpellier SupAgro), Campus international de Baillarguet, CS 30016, F-34988 Montferrier-sur-Lez cedex, France
}

\begin{abstract}
The early stages of invasion involve demographic bottlenecks that may result in lower genetic variation in introduced populations as compared to source population/s. Low genetic variability may decrease the adaptive potential of such populations in their new environments. Previous population genetic studies of invasive species have reported varying levels of losses of genetic variability in comparisons of source and invasive populations. However, intraspecific comparisons are required to assess more thoroughly the repeatability of genetic consequences of colonization events. Descriptions of invasive species for which multiple introductions from a single source population have been demonstrated may be particularly informative. The western corn rootworm (WCR), Diabrotica virgifera virgifera, native to North America and invasive in Europe, offers us an opportunity to analyse multiple introduction events within a single species. We investigated within- and between-population variation at eight microsatellite markers in WCR in North America and Europe to investigate the routes by which WCR was introduced into Europe, and to assess the effect of introduction events on genetic variation. We detected five independent introduction events from the northern USA into Europe. The diversity loss following these introductions differed considerably between events, suggesting substantial variation in introduction, foundation and/or establishment conditions. Genetic variability at evolutionarily neutral loci does not seem to underlie the invasive success of WCR in Europe. We also showed that the introduction of WCR into Europe resulted in the redistribution of genetic variance from the intra- to the interpopulational level contrary to most examples of multiple introductions.
\end{abstract}

Keywords: founder effects, invasion success, loss of genetic variation, microsatellites, multiple introductions, redistribution of genetic variance

Received 17 January 2008; revision received 15 May 2008; accepted 18 June 2008

\section{Introduction}

Invasive species may present a major threat to biodiversity, ecosystem integrity (reviewed in McKinney \& Lockwood 1999; Olden et al. 2004), agriculture and fisheries (Pimentel et al. 2001). They may also present public health risks (e.g. Ruiz et al. 2000). We therefore need to improve our understanding of the processes underlying their success or failure. Another reason that motivates the study of biological

Correspondence: Marc Ciosi, Fax: +33 4923864 01; E-mail: marc.ciosi@sophia.inra.fr invasions is that recently introduced species may be seen as natural experiments, providing opportunities to investigate the genetic consequences of the early stages of colonization (e.g. Sax et al. 2005; Cadotte et al. 2006). The repeated introductions of a given species, in different geographical locations, provide spatial replicates of colonization (reviewed in Bossdorf et al. 2005; Roman \& Darling 2007). In such cases, it is possible to evaluate the repeatability of genetic consequences of colonization events (Ayala et al. 1989) by comparing different introduced populations.

It is difficult to detect biological invasions in their early stages (small number of founder individuals, long period 
with low population densities) and such invasions may also be unpredictable (the location and time of introduction are generally unknown), making them difficult to study directly (e.g. Grevstad 1999). There are therefore few detailed descriptions of population dynamics and structure during early phases of invasion and founder events remain largely unstudied. Analysis of the genetic variation of recently introduced and source populations can be used to provide indirect information about the first steps of the invasion process. The initial phases of invasion (introduction and establishment) are often associated with a founder effect a loss of genetic variability with respect to the source population, due to the small number of founder individuals and small population size during the first few generations (e.g. Dlugosch \& Parker 2008). By contrast, multiple introductions may increase the genetic variability of the invasive population especially when several genetically differentiated source populations contribute to the invasion (e.g. Facon et al. 2003; Kolbe et al. 2004; Kang et al. 2007). Analyses of the genetic variability of invading populations hence provide insight into the historical demography of the introduction and establishment phases of invasion.

Ecological conditions in the new environment may vary greatly from those in the area of origin, representing an adaptational challenge for newly introduced populations (reviewed in Reznick \& Ghalambor 2001; Schierenbeck \& Aïnouche 2006). Within-population genetic variability, thought to determine the capacity of populations to adapt to new environments, may therefore be crucial to successful invasion although some examples of successful invaders display very low genetic variability (reviewed in Novak \& Mack 2005; Wares et al. 2005). This hypothesis, although intuitive, has rarely been tested with actual introduced populations, due to the lack of reports of failed invasions and of genetic patterns of repeated independent introductions of a single species (Lockwood et al. 2005; but see Stockwell et al. 1996; Voisin et al. 2005; Kelly et al. 2006; Roman 2006).

The western corn rootworm (WCR), Diabrotica virgifera virgifera LeConte (Coleoptera: Chrysomelidae), is a major pest of cultivated corn, Zea mays L. Most of the damage to this crop is caused by larvae feeding on the root system of maize (Levine et al. 2002). This pest species probably originated in Central America (Smith 1966; Branson \& Krysan 1981), but the current southernmost limit of its modern distribution is northern Mexico (Krysan \& Smith 1987). It is likely that WCR evolved with corn in Mexico and reached what is now the southwestern USA about 3000 years ago with the introduction of its host plant (Krysan \& Smith 1987). More recently, WCR rapidly expanded its range from the southwestern region of the US Corn Belt in the 1950s, reaching the east coast of North America during the 1980s (Metcalf 1983; Spencer et al. 2005). It was recently introduced into Europe, where it was first observed near Belgrade, Serbia in 1992. An international network has since monitored its spread throughout Europe (Kiss et al. 2005a), and has provided an annually updated, detailed description of the distribution and spread of WCR in Europe. This monitoring is mandatory within the European Union and serve as a powerful tool to detect new introductions of WCR into Europe, making it unlikely that a large and persistent outbreak remains undetected. Two types of infested area have been identified: (i) areas of continuous spread [in Central and southeastern (CSE) Europe and northwestern (NW) Italy] that correspond to 'successful invasions', and (ii) several disconnected outbreaks that did not persist over time and/or did not spread. These outbreaks correspond to 'unsuccessful invasions'. The CSE Europe outbreak now extends over 11 countries, from Austria to the Ukraine and from southern Poland to southern Serbia. The first disconnected outbreak was discovered near Venice in 1998. Since then, new disconnected outbreaks have been detected, in NW Italy and Switzerland (canton Ticino) in 2000, northeastern (NE) Italy in 2002 (Pordenone) and 2003 (Udine), Northern Italy (Trentino), Eastern France, Switzerland, Belgium, the UK and the Netherlands in 2003, and the Parisian region, France in 2002, 2004 and 2005. Unsuccessful invasive outbreaks can be classified in two categories. Outbreaks detected in north Switzerland, Belgium, Netherlands and the Parisian region did not persist over time and are currently extinct. We refer to these as 'extinct outbreaks'. Outbreaks detected in NE Italy, eastern France and the UK have persisted over time but did not undergo geographical expansion. We refer to these as 'established but nonspreading outbreaks'. A recent population genetic study by Miller et al. (2005) showed that the different WCR introduction foci in Europe probably resulted from both the intracontinental movement of insects and repeated transatlantic introductions from North America. Miller et al. (2005) suggested that independent introductions were probably responsible for at least the CSE Europe, NW Italy and Paris-2002 outbreaks. WCR thus provides us with an opportunity to analyse introduced populations in the early phases of invasion, and represents an ideal biological model for assessing the details and repeatability of genetic consequences of colonization events, through the comparison of different introduced populations. Miller et al. (2005) focused on the statistical inference of WCR introduction routes and did not describe genetic variation within and between the populations they investigated. Moreover, they did not genetically study several European foci as well as American populations of WCR. There is thus so far no precise description of the worldwide geographical distribution of the genetic variability of WCR.

We re-analysed the data of Miller et al. (2005), investigated additional American and European WCR samples, so as to cover most of the geographical distribution of D. virgifera virgifera, and addressed the following issues: (i) we inferred the most probable source population and 
Table 1 Western corn rootworm population samples used in this study, with statistics summarizing genetic variation within populations

\begin{tabular}{|c|c|c|c|c|c|c|c|c|}
\hline \multirow[b]{2}{*}{ Geographical area } & \multirow[b]{2}{*}{ Sample name } & \multirow[b]{2}{*}{ Location } & \multirow[b]{2}{*}{1 st obs. } & \multirow[b]{2}{*}{$N$} & \multirow{2}{*}{$\begin{array}{l}\text { Collection } \\
\text { year }\end{array}$} & \multicolumn{3}{|l|}{$A$} \\
\hline & & & & & & $\mathrm{DC}$ & MSS & $H$ \\
\hline \multirow[t]{5}{*}{ North America } & Mexico & Registrillo, Durango, Mexico & $<1940$ & 14 & 2001 & $7.250(3.694)$ & $6.154(2.716)$ & 0.753 \\
\hline & Arizona & Willcox, Arizona, USA & $<1974$ & 40 & 1998 & $9.000(4.928)$ & $5.524(2.311)$ & 0.681 \\
\hline & Texas & New Deal, Texas, USA & $<1980$ & 51 & 2004 & $8.125(4.673)$ & $5.493(2.650)$ & 0.675 \\
\hline & Illinois & Champaign, Illinois & $<1974$ & 60 & 2003 & $7.250(5.120)$ & $4.806(2.189)$ & 0.649 \\
\hline & Pennsylvania & Bellefonte, Pennsylvania & $<1985$ & 62 & 2003 & $7.500(5.043)$ & $4.798(2.366)$ & 0.644 \\
\hline $\begin{array}{l}\text { Central southeastern } \\
\text { Europe area of spread }\end{array}$ & CSE Europe & Belgrade Airport, Serbia & 1992 & 38 & 2003 & $3.375(1.685)$ & $2.912(1.257)$ & 0.453 \\
\hline \multirow{9}{*}{$\begin{array}{l}\text { Western European } \\
\text { disconnected outbreaks }\end{array}$} & Friuli & Buttrio, Italy & 2003 & 27 & 2003 & $1.750(0.707)$ & $1.711(0.634)$ & 0.293 \\
\hline & Trentino & Storo, Italy & 2003 & 44 & 2004 & $2.875(1.959)$ & $2.430(1.449)$ & 0.361 \\
\hline & Piedmont & Oleggio, Italy & 2000 & 40 & 2003 & $4.250(3.151)$ & $3.252(2.060)$ & 0.420 \\
\hline & Lombardy & Lentate, Italy & 2001 & 44 & 2003 & $3.250(2.816)$ & $2.322(1.499)$ & 0.347 \\
\hline & SW & Balerna, Switzerland & 2000 & 45 & 2003 & & & \\
\hline & Paris-1 & Roissy Airport, France & 2002 & 19 & 2003 & $3.750(1.753)$ & $3.160(1.162)$ & 0.510 \\
\hline & Paris-2 & Pierrelaye, France & 2004 & 74 & 2004 & $3.750(1.581)$ & $2.931(0.722)$ & 0.534 \\
\hline & Alsace & Schwindratzheim, France & 2003 & 9 & 2003 & $4.625(1.996)$ & $4.625(1.996)$ & 0.581 \\
\hline & UK & Slough, United Kingdom & 2003 & 36 & 2005 & $5.750(3.770)$ & $4.374(2.212)$ & 0.612 \\
\hline
\end{tabular}

$1^{\text {st }}$ obs., year of first observation of the outbreak. $N$, number of individuals analysed per sample. $A$, average number of alleles per locus; standard deviations across loci are shown in brackets. $A$ is given by direct counts (DC) and based on multiple subsampling (MSS), accounting for sample size variation. MSS is given for the smallest sample size $(n=9)$. $H$, mean expected heterozygosity (Nei 1987). Significant deviation from Hardy-Weinberg Equilibrium was observed for the Paris-2 sample only $(P<0.0001)$.

introduction route of each European outbreak; (ii) we documented the effect of multiple introductions on the overall genetic variance of WCR in its introduction range in Europe (more specifically, we analysed the balance between intra- and interpopulation genetic variance in the introduced range compared to the source geographical area); (iii) finally, we evaluated the intraspecific repeatability of losses of genetic variation between independent introductions by comparing different outbreaks originating from the same source population. Based on this analysis, we evaluated the relationship between the invasion success and genetic variation of introduced populations of WCR.

\section{Materials and methods}

\section{Sample collection}

Samples of WCR from European outbreaks were collected at 10 sites in five countries (see details in Table 1 and Fig. 1). In CSE Europe, the sample studied was collected close to the site at which this species was first observed in Europe - Belgrade Airport in Serbia (only one sample from CSE Europe was used because unpublished results have shown little or no genetic differentiation between sites in this outbreak). The European samples from CSE Europe, Friuli, Piedmont, Paris-2, and Alsace (eastern France) studied here were those investigated by Miller et al. (2005). We also sampled a site (Trentino) corresponding to a small disconnected outbreak observed in 2003 in northern Italy and two sites corresponding to the large outbreak in NW Italy: Lentate in Italy (Lombardy) and Balerna in southern Switzerland (SW). In this area, WCR was first detected in 2000 in Lombardy. The sample collected close to Roissy Airport near Paris (Paris-1 sample) studied by Miller et al. (2005) was small. We therefore obtained and genotyped additional individuals from this site. We re-processed the individuals collected by Miller et al. (2005) from Alsace, France, for which microsatellite data were missing, to try to fill in the gaps where possible. Finally, we included a sample from the outbreak near Heathrow Airport (London, UK) first detected in 2003 in the analysis. These European sampling sites correspond to all the outbreaks detected in Western Europe between the first observation of WCR in Europe and 2006, with the exception of three outbreaks for which no beetles were detected after 2003: the outbreaks discovered in Belgium and the Netherlands in 2003, and the outbreak detected near Venice in NE Italy in 1998. In three of the outbreaks (Alsace, Paris-2, and Friuli), sampling was performed before any eradication attempts. In the four other outbreaks (CSE Europe, NW Italy, UK and Pairs-1), eradication attempts occurred before the sampling. In these latter outbreaks, eradication activities principally consist of aerial application of pyrethroid insecticides and the establishment of crop rotation in subsequent years.

In North America, we choose a sampling scheme that allows the description of the genetic structure of WCR in its 

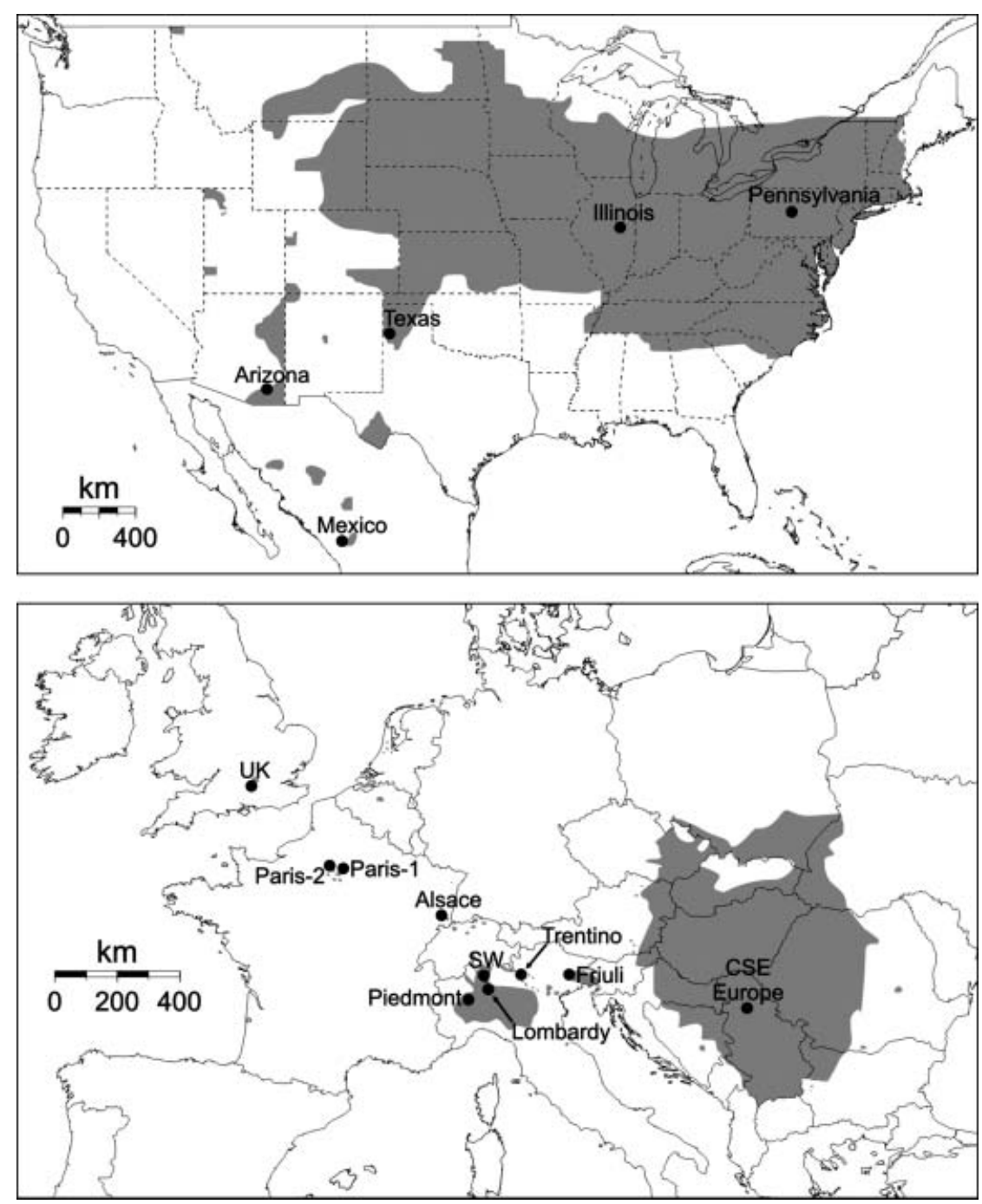

Fig. 1 Geographical distribution of WCR in 2006 and sampling sites. Distribution area, with sites at which WCR was observed for at least 1 year is shown in grey. native continent. Kim \& Sappington (2005a) showed that there is little to no genetic differentiation between US populations of WCR form Texas to the East Coast of the USA; Krysan \& Smith (1987) showed that the state of Durango, in northern Mexico, is the southernmost limit of the geographical distribution of WCR in America. For our analysis, we choose samples from locations that represent the genetic variability of WCR from Texas to the East Coast of the USA and that were previously analysed by Kim \& Sappington (2005a), namely Pennsylvania, Illinois, Texas. To those three samples, we added samples collected at the southernmost limit of WCR distribution in North America and at an intermediate locality in Arizona near the border with Mexico.

In invasive outbreaks (CSE Europe and NW Italy), where population densities were high, adult beetles were sampled with aspirator devices or butterfly nets. In the other outbreaks (UK, the three French outbreaks and Friuli), because of the very low population densities, WCR adults were trapped with sexual pheromone-based sticky traps used for WCR monitoring in Europe. When beetles were collected with aspirator devices or butterfly nets, the insects were sampled within 1 day in a unique maize field. For each site sampled using the trap method, the collection of individual beetles could be separated by a few days and a few kilometres. The number of individuals in each sample is given in Table 1.

\section{DNA extraction and microsatellite analysis}

Template material for polymerase chain reaction (PCR) amplification of microsatellites was obtained using three different protocols. DNA was prepared from a single leg per individual in $25 \mu \mathrm{L}$ 15\% Chelex (Bio-Rad) supplemented with $2 \mu \mathrm{g} / \mu \mathrm{L}$ proteinase $\mathrm{K}$ (Euromedex), as described by Estoup et al. (1996) for two individuals from the Paris-1 sample. For the other insects of the Paris- 1 sample and all individuals from Alsace, DNA was extracted from the thorax of each specimen, using the DNeasy tissue kit 
(QIAGEN). For the other insects, the 'salting out' rapid extraction protocol (Sunnucks \& Hales 1996) was used to extract DNA from the head of each individual. Before using the latter two extraction protocols, individuals were washed at least three times in $0.065 \% \mathrm{NaCl}$, to remove ethanol from the tissues. Subsequently, each head or thorax was cut and placed in a $1.5-\mathrm{mL}$ microcentrifuge tube, frozen in liquid nitrogen and pulverized with a micropestle. DNA was extracted from the pulverized material.

Six dinucleotide (DVV-D2, DVV-D4, DVV-D11, DVV-D5, DVV-D8, DVV-D9) and two trinucleotide (DVV-T2 and DVV-ET1) microsatellite loci (Miller et al. 2005; Kim \& Sappington 2005b) were amplified in two separate multiplex PCR reactions, and analysed as described by Miller et al. (2007). Allele scoring was standardized between this study and that of Kim \& Sappington (2005a), using a panel of common reference DNA samples (not shown), as reported by Kim et al. (2008).

\section{Summary statistics of genetic variation}

Genetic variation within populations was quantified by determining the mean number of alleles per locus, $A$, and mean expected heterozygosity, $H$ (Nei 1987). $A$ is highly dependent on sample size (e.g. Leberg 2002), rendering comparisons between populations potentially problematic. We therefore used GENCLONE 1.0 (Arnaud-Haond \& Belkhir 2007 ) to estimate $A$ for a sample size between one and the actual size of the sample considered, using the multiple subsampling method (Leberg 2002). Exact tests for population differentiation (Raymond \& Rousset 1995a) were carried out for all pairs of populations, with GENEPOP (Raymond \& Rousset 1995b). As this test involves non-orthogonal and multiple comparisons, a sequential Bonferroni correction was applied (Sokal \& Rolf 1995; p. 236). GENEPOP was also used to calculate pairwise $F_{\mathrm{ST}}$ estimates (Weir \& Cockerham 1984) as statistics summarizing genetic variation between populations, and to test for Hardy-Weinberg equilibrium, with the probability test approach.

\section{Identification of source populations}

The most probable source population for each European outbreak was identified by calculating the mean multilocus individual assignment likelihood of each introduced outbreak sample $i$ to each sample of possible source populations s (hereafter denoted $L_{\mathrm{i} \rightarrow \mathrm{s}}$; see Pascual et al. 2007; Rannala \& Mountain 1997). Pascual et al. (2007) showed, by computer simulation, that $L_{\mathrm{i} \rightarrow \mathrm{s}}$ efficiently identifies the actual source population of a recently introduced population, even if the candidate source populations display only weak differentiation (i.e. display low $F_{\mathrm{ST}}$ ) and if the introduced population endured a strong founder event. More specifically, $L_{\mathrm{i} \rightarrow \mathrm{s}}$ values remain similar in expectation for a large range of founder event intensities, although its variance increases, as high-frequency alleles tend to be retained after a founder event. Individuals in introduced populations subject to bottlenecks therefore tend to bear alleles present at high frequency in the source population, resulting in high individual assignment likelihoods in the actual source population. $L_{\mathrm{i} \rightarrow \mathrm{s}}$ values were calculated with GENECLAss 2 (Piry et al. 2004). No ad hoc statistical test has yet been described for formally comparing mean individual assignment likelihoods (as well as $F_{\mathrm{ST}}$ ). Moreover, nonparametric tests, such as the Friedman analysis of variance by rank or pairwise Wilcoxon signed-rank test, using the locus as the repetition unit, are not sufficiently powerful (due to limited number of loci) for such comparisons in the context of the present study.

Therefore, for each European outbreak, the most probable source population was simply identified as that with both the highest $L_{\mathrm{i} \rightarrow \mathrm{s}}$ value and the lowest $F_{\mathrm{ST}}$-value with this outbreak. However, as only a small fraction of the large geographical range of WCR in North America has been sampled, the selected populations may not be the 'true' source population per se, corresponding instead simply to the most probable of the source populations studied.

Multiple introductions in a single location are expected to leave a genetic signature for migrants originating from sources genetically differentiated from the outbreak considered. Because of the number of loci we used, only migrants of first generation would be detectable (see Rannala \& Mountain 1997 for a discussion on the power of statistical tests of assignment). To detect multiple introductions, two methods were therefore applied: (i) the detection method of first-generation migrants of Paetkau et al. (2004) implemented in GENECLAss 2 (version 2.0, Piry et al. 2004) was used. 10000 individuals were simulated per population and the likelihood calculation of Rannala \& Mountain (1997) was used. The statistics used was the individual assignment likelihood to the population where the individual was sampled. (ii) A multimodal distribution of the individual assignment likelihood value of an outbreak into each putative source population can be observed when first-generation migrants introduced from different sources are frequent in the outbreak (unpublished results). We thus tested the unimodality of the distribution of assignment likelihood value of individuals belonging to each European population into each possible source population (normality test of the data using a Kolmogorov-Smirnov test).

\section{Results}

The Lombardy and SW samples were considered as a single population sample, as they displayed no significant genetic differentiation (see below). The Pennsylvania and Illinois samples are referred to as the 'northern US sample' below. Microsatellite allele frequencies for each locus and 
population are listed in Table S1. The mean number of alleles per locus and expected heterozygosity are given for each population in Table 1.

\section{Genetic variation within populations}

The complete data set of WCR samples showed substantial polymorphism, with a mean of 12.375 alleles per locus over all samples. The number of alleles varied from 6 for the DVV-D5 and DVV-ET1 loci to 23 for the DVV-D8 locus. All 99 observed alleles were present in North America and 58 of these alleles were detected in Europe. In North America, all loci were polymorphic in all samples; whereas in Europe, some loci were monomorphic in some samples (e.g. the DVV-D5 locus, which was monomorphic in CSE Europe and all Italian samples; see Table S1). Significantly fewer alleles were found in Europe than in North America (mean $A$ when pooling all populations within each continent $=7.250$ and 12.375, respectively; Wilcoxon's signed-rank test, $P=0.008$ ), and expected heterozygosity (mean among populations) was lower in Europe than in America (0.457 and 0.681 , respectively; Wilcoxon's signed-rank test, $P=0.008$ ).

The standardization of $A$ as a function of smallest sample size (i.e. MSS in Table 1) made it possible to compare samples. In North America, the samples from Mexico, Texas and Arizona were genetically more diverse than those from the northern USA (Illinois and Pennsylvania) (Wilcoxon's signed-rank tests, $P \leq 0.024)$. Expected heterozygosities ( $H$ in Table 1 ) in North America range from 0.644 (Pennsylvania) to 0.753 (Mexico). $H$ was significantly higher in Mexico than in Texas and in the northern USA samples (Wilcoxon's signed-rank tests, $P \leq 0.04$ ).

In Europe, $A$ was highly heterogeneous between samples, varying from 1.75 (MSS = 1.711) in Friuli to 5.75 (MSS $=4.374$ ) in the UK (Table 1). The UK and Alsace samples had significantly higher allelic diversities than any other European sample (Wilcoxon's signed-rank tests on MSS, $P \leq 0.024$ for each test) except for comparisons of the UK sample to both the Parisian samples. Mean expected heterozygosity ranged from low to medium values in Europe (about 0.3 in Friuli to 0.6 in Alsace and the UK). No significant differences of genetic variability could be detected between extinct (Paris-1 and 2), established but not spreading (UK, Alsace and Friuli) and invasive (NW Italy and CSE Europe) outbreaks (global test: Friedman's test by rank performed over loci, $P>0.5$ for both $A$ and $H$; invasive vs. others: Wilcoxon's test over loci $P \geq 0.164$ for both $A$ and $H$; and extinct vs. others: Wilcoxon's test over loci, $P \geq 0.194$ for both $A$ and $H$ ).

\section{Genetic variation between populations}

Most pairwise comparisons showed significant genetic differentiation $(P<0.05$; Table 2$)$, with large to very large
$F_{\mathrm{ST}}$ estimates $($ mean $=0.16, \mathrm{SD}=0.11)$. In North America, pairwise genetic differentiation ranged from weak in the northern USA $\left(F_{\mathrm{ST}}=0.01\right)$ to considerable between northern USA and Mexico (mean $F_{\mathrm{ST}}=0.11, \mathrm{SD}=0.01$ ). Most sample pairs in Europe displayed significant differentiation, with high $F_{\mathrm{ST}}$ values (mean $=0.19, \mathrm{SD}=0.12$ ), with the exception of SW-Trentino, SW-Lombardy and Trentino-Lombardy pairs, for which $F_{\mathrm{ST}}$ estimates were below 0.01 (mean $=0.002$, $\mathrm{SD}=0.003)$. SW and Lombardy were not significantly differentiated (Fisher's exact test, $P=0.86$ ), with an $F_{\mathrm{ST}}$ value of zero, and were hence pooled together for subsequent analysis.

A high level of genetic differentiation was observed for most intercontinental comparisons (mean pairwise $F_{\mathrm{ST}}$ values $=0.15, \mathrm{SD}=0.09$ ), with the exception of comparisons between the UK sample and samples from the northern USA, for which an $F_{\mathrm{ST}}$ value of only about 0.01 was obtained. Intercontinental pairwise $F_{\mathrm{ST}}$ decreased from the southwest to the northeast for American samples [mean $F_{\mathrm{ST}}(\mathrm{SD})$ of 0.25 (0.09), 0.17 (0.07), 0.11 (0.06), 0.12 (0.07), 0.10 (0.06), for comparisons of the European samples with Mexico, Arizona, Texas, Illinois and Pennsylvania sample, respectively].

\section{Identification of the most representative source populations}

The hypothesis of a single source population for each European outbreak was never rejected. All 77 normality tests performed suggest that assignment likelihood values of European individuals into the 11 potential source populations are approximately normally distributed (Kolmogorov-Smirnov tests, $P>0.05$ for all tests), so that the unimodality of the individual assignment likelihood distributions was never rejected. Using the method of Paetkau et al. (2004), we found that two European individuals were classified as first-generation migrants $(P<0.05$ for both individuals), one in the UK, statistically assigned into Texas or Pennsylvania $[-10 \log (L)=4.55$ and 4.56 , respectively], and one in Paris-1 assigned into UK. These migrants probably correspond to multiple introductions from the most representative source population identified for each of these outbreaks. Overall, we found no evidence for multiple introductions from various differentiated source populations into the European outbreaks.

The most probable source population of each European sample $i$ was identified by analysing the $F_{\mathrm{ST}}$ values of all sample pairs including sample $i$ and all mean individual assignment likelihoods of sample $i$ into sample $s\left(L_{i \rightarrow s}\right.$ values expressed on a -log scale). The deduced most probable source population for each outbreak was identified as the sample with both the highest $L_{\mathrm{i} \rightarrow \mathrm{s}}$ and the lowest $F_{\mathrm{ST}}$ value (Table 2). These criteria identified the northern USA population as the most representative source population for CSE Europe, the UK, Paris-2 and Alsace. For all the NW Italian 
Table 2 Pairwise estimate of $F_{\mathrm{ST}}$ (Weir \& Cockerham 1984) and mean individual assignment likelihood ( $L_{\mathrm{i} \rightarrow \mathrm{s}}$ ) of each sample to each potential source population (Pascual et al. 2007)

\begin{tabular}{|c|c|c|c|c|c|c|c|c|c|c|c|c|c|c|c|}
\hline & \multicolumn{14}{|c|}{ Potential source populations } & \multirow{3}{*}{$\begin{array}{l}\text { Most likely } \\
\text { source } \\
\text { population }\end{array}$} \\
\hline & \multicolumn{5}{|c|}{ North America } & \multicolumn{9}{|l|}{ Europe } & \\
\hline & Mexico & Arizona & Texas & Illinois & Pennsylvania & CSE Europe & Friuli & Trentino & Lombardy-SW & Piedmont & Paris-1 & Paris-2 & Alsace & UK & \\
\hline Arizona & 0.0590 & - & - & - & - & - & - & - & - & - & - & - & - & - & \\
\hline Texas & 0.0870 & 0.0295 & - & - & - & - & - & - & - & - & - & - & - & - & \\
\hline Illinois & 0.1002 & 0.0501 & 0.0164 & - & - & - & - & - & - & - & - & - & - & - & \\
\hline Pennsylvania & 0.1177 & 0.0638 & 0.0169 & 0.0094 & - & - & - & - & - & - & - & - & - & - & \\
\hline CSE Europe & $0.224(16.410)$ & $0.167(16.770)$ & $0.103(8.974)$ & $0.109(8.259)$ & $0.095(7.627)$ & - & $0.116(11.143)$ & $0.264(17.760)$ & $0.276(19.266)$ & $0.197(13.196)$ & $0.257(11.080)$ & $0.148(12.130)$ & $0.118(8.960)$ & $0.126(8.581)$ & Pennsylvania \\
\hline Friuli & 0.319 (16.649) & $0.276(18.605)$ & $0.226(10.048)$ & $0.229(9.175)$ & $0.218(8.152)$ & $0.116(4.863)$ & - & $0.43(19.620)$ & $0.429(20.986)$ & $0.357(15.354)$ & 0.439 (14.479) & 0.278 & $0.267(9.425)$ & 0.285 (11.301) & CSE Europe \\
\hline Trentino & $0.331(16.010)$ & $0.222(13.740)$ & $0.151(8.674)$ & $0.17(8.498)$ & $\underline{0.13(7.708)}$ & $0.264(11.534)$ & $0.43(18.465)$ & - & $0.005(3.812)$ & $0.028(4.359)$ & $0.299(12.051)$ & $0.17(9.634)$ & $0.256(12.248)$ & $0.149(7.851)$ & Pennsylvania $^{*}$ \\
\hline Lombardy-SW & 0.37 & $0.257(14.143)$ & $0.178(8.895)$ & $0.202(9.030)$ & $\underline{0.152(7.922)}$ & $0.276(12.026)$ & $0.429(18.463)$ & $0.005(3.784)$ & - & $0.023(4.400)$ & $0.324(12.297)$ & 0.203 & $0.27(12.280)$ & $0.173(7.984)$ & Pennsylvania* \\
\hline Piedmont & $0.285(16.214)$ & $0.177(13.497)$ & $0.103(8.660)$ & $0.116(8.396)$ & $\underline{0.082(7.672)}$ & $0.197(12.059)$ & $0.357(18.382)$ & $0.028(6.957)$ & $0.023(7.354)$ & - & $0.224(11.380)$ & 0.133 & $0.161(11.241)$ & $0.09(7.814)$ & Pennsylvania* \\
\hline Paris-1 & $0.223(15.938)$ & $0.136(11.390)$ & $0.105(9.045)$ & $0.068(7.553)$ & $0.087(7.706)$ & $0.257(12.784)$ & $0.439(23.903)$ & $0.299(18.588)$ & $0.324(21.812)$ & $0.224(11.179)$ & - & $0.154(11.061)$ & 0.095 (7.952) & $0.066(7.148)$ & UK \\
\hline Paris-2 & $0.207(16.384)$ & $0.143(13.127)$ & $0.074(9.342)$ & $0.069(9.140)$ & $0.052(8.189)$ & $0.148(11.703)$ & $0.278(18.206)$ & 0.17 (14.494) & $0.203(16.341)$ & $0.133(11.507)$ & 0.154 & - & $0.141(11.201)$ & $0.086(9.912)$ & Pennsylvania \\
\hline Alsace & $0.100(14.648)$ & $0.06(12.215)$ & $0.042(9.660)$ & $0.021(8.301)$ & $0.046(8.940)$ & $0.118(13.178)$ & $0.267(19.268)$ & $0.256(19.240)$ & $0.27(21.460)$ & $0.161(12.901)$ & $0.095(10.165)$ & 0.141 & - & $0.032(8.928)$ & Illinois \\
\hline UK & $0.128(16.125)$ & $0.066(13.203)$ & $0.022(9.077)$ & $0.008(8.097)$ & $0.013(8.436)$ & $0.126(13.840)$ & $0.285(22.653)$ & $0.149(17.122)$ & $0.173(19.244)$ & 0.09 (11.848) & $0.066(10.887)$ & 0.086 & $0.032(9.768)$ & - & Illinois \\
\hline
\end{tabular}

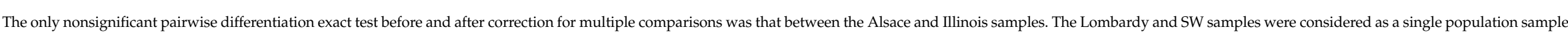

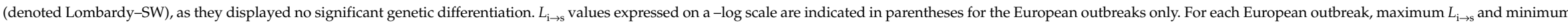

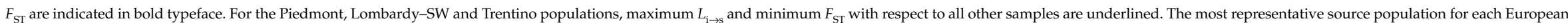
outbreak is indicated in the last column. * indicates the most likely source of the single outbreak corresponding to the Piedmont, Lombardy-SW and Trentino samples. 


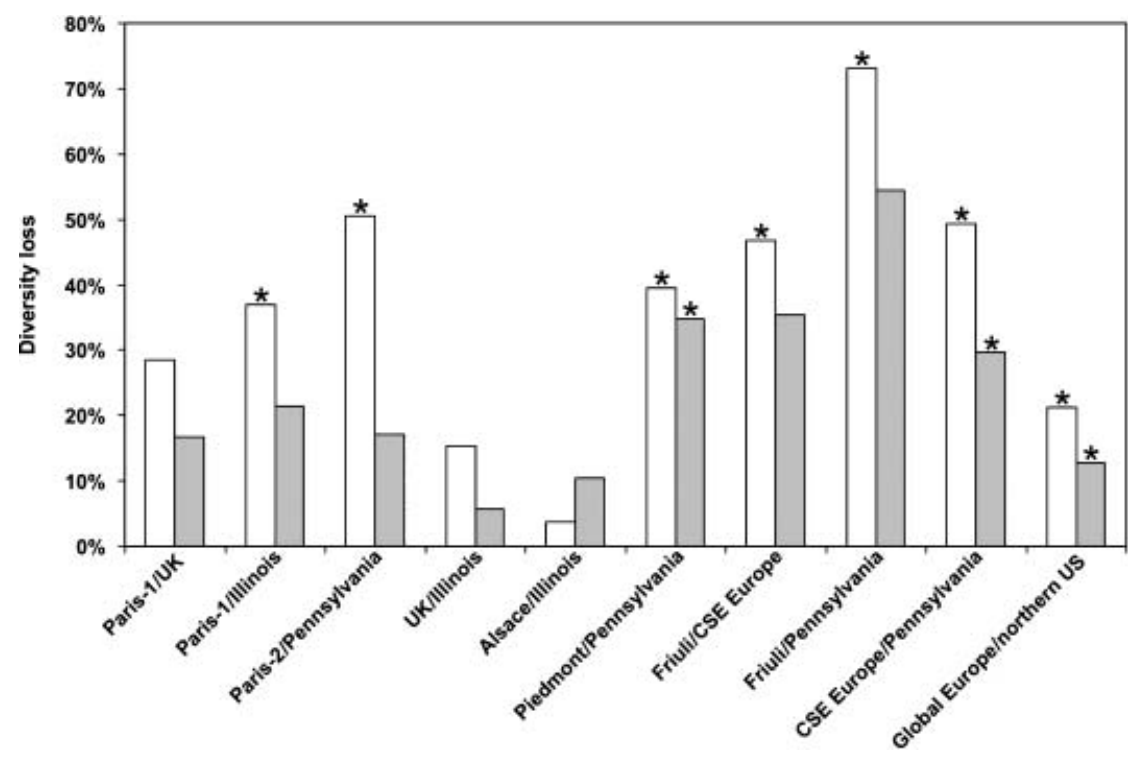

Fig. 2 Loss of genetic diversity in European invasive populations of WCR with respect to their most representative source populations. White bars correspond to the percentage allelic diversity loss, corrected for sample size, and grey bars correspond to the percentage mean expected heterozygosity (gene diversity; Nei 1987) loss. Significant diversity losses are indicated by asterisks (based on Wilcoxon's signed-rank tests). For the two European outbreaks probably originating from a secondary introduction from Europe (Friuli and Paris-1), diversity loss with respect to northern USA populations is also shown to illustrate the effect of successive introductions. For comparisons of the entire area of invasion in Europe with the most probable source of the invasion, we pooled all outbreaks originating from the northern US into a single sample referred to as global Europe (with only the Piedmont sample included to represent the NW Italian outbreak).

and Swiss samples, minimum $F_{\mathrm{ST}}$ estimates and maximum $L_{\mathrm{i} \rightarrow \mathrm{s}}$ identified a sample from the same region as the most probable source. If these NW Italian and Swiss samples were considered to correspond to a single outbreak, then their most probable source population was Pennsylvania in the northern USA. Both $F_{\mathrm{ST}}$ and $L_{\mathrm{i} \rightarrow \mathrm{s}}$ values suggested that the Paris-1 population originated in the UK, and that the Friuli population originated in CSE Europe.

A detailed investigation of allelic frequency distributions (see Table S1) supported our identification of the most probable source population for each outbreak. A sample from the source population should contain all the alleles present in samples corresponding to introductions from that population. All the alleles of the Friuli population were found in CSE Europe, and all the alleles of the CSE Europe, UK, Paris-2 and NW Italy samples were found in the northern USA sample. A single rare allele of the Paris1 population (allele 207 of DVV-D2) was not present in the sample of its most probable source, the UK. Allelic distributions also made it possible to reject alternative hypotheses. For instance, the UK is unlikely to be the source of the Piedmont population, given the presence of allele 198 at locus DVV-D11 and alleles 208 and 234 at locus DVV-D8 in the Piedmont population, and the absence of these alleles in the UK. The UK is also unlikely to be the source of the Paris-2 population, as alleles 198 at locus DVV-D11, 152 at DVV-D9 and 214 at DVV-D8 were present in the Paris-2 population but absent from the UK sample.

\section{Comparison between introduced populations and their most representative source populations}

The mean number of alleles was smaller for all European outbreak samples than for their inferred source populations (Table 1 and Fig. 2). MSS was, on average, 38.2\% (SD = 20.5\%) lower and $H$ was $25.1 \%(S D=15.1 \%)$ lower in European populations than in their inferred sources (Fig. 2). The decrease in the number of alleles was significant in all cases (Wilcoxon's signed-rank tests, $P=0.016$ for all tests) other than for comparisons of the samples from Alsace and the UK with the sample from Illinois (Wilcoxon's signed-rank tests, $P=0.25$ and 0.156 , respectively) and for the comparison of the Paris-1 and UK populations (Wilcoxon's signedrank test, $P=0.062$ ). A significant decrease in expected heterozygosity was observed only for comparisons of the Piedmont and Pennsylvania populations and the Friuli and CSE Europe populations (Wilcoxon's signed-rank tests, $P=0.008$ and 0.016 , respectively).

The loss of variability differed markedly between outbreaks (Fig. 2). Genetic bottlenecks were weakest for the UK and Alsace populations, with a loss of less than $16 \%$ MSS, whereas the other outbreak populations showed MSS losses exceeding 28\% (Fig. 2). The loss of expected heterozygosity was also highly heterogeneous, with a loss of less than $18 \%$ for Parisian samples and samples from the UK and Alsace and a loss of more than $29 \%$ for Italian samples and CSE Europe. 


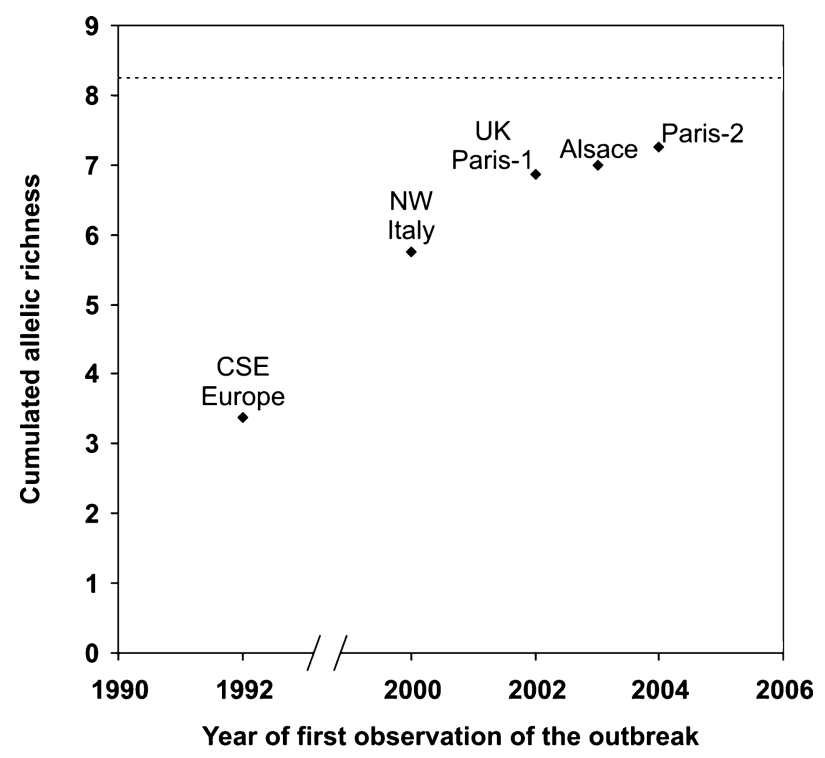

Fig. 3 Cumulated allelic richness (mean allele number per locus) in Europe during the invasion by the western corn rootworm. The dotted line shows the allelic richness of the most representative native source population (northern USA).

When considered individually, European outbreak populations were generally significantly less variable than northern USA sample (see above). However, overall, the global European gene pool contained almost as much genetic variation as that of the northern USA sample. The number of alleles was similar in the northern USA sample and the global European gene pool $(A=8.25$ and 7.25, respectively, and MSS $=8.25$ and 6.23, respectively; Wilcoxon's signed-rank test, $P=0.218$ and 0.032 for $A$ and MSS) (Fig. 2). The 11 alleles (concerning all eight loci) present in the northern USA sample but not in Europe were all rare (frequency $=2 \%$ ). Expected heterozygosity was nevertheless significantly lower in the global European gene pool (0.457) than in the northern USA sample (0.647) (Wilcoxon's signed-rank test, $P=0.008$ ).

The UK and Alsace populations were genetically very variable (Table 1) and had a variability similar to that of the northern USA sample. However, they were far from being solely responsible for the high allelic diversity found within the global European gene pool. Removing the UK and Alsace populations from the global European gene pool decreased the number of alleles by only $12 \%$ (from 58 to 51 alleles). The global European gene pool was rapidly increased by successive introductions (Fig. 3): $46.5 \%$ of the 58 European alleles arrived with the first introduction of WCR into Serbia in 1992, and 33\% of the total allelic diversity (19 additional alleles) was added during the second recorded introduction (in NW Italy in 2000). Subsequent introductions added $15.5 \%$ (nine additional alleles in the UK and Paris-1 introductions), 2\% (one allele in Alsace) and 3\% (two alleles in the Paris-2 population) to the overall allelic diversity of European populations. Hence, allelic variability doubled in a very short period, between 1992 - the year in which WCR was first detected (27 alleles) - and 2004 (58 alleles). On average, the genetic diversity loss was not significantly different between outbreaks that had been subjected to eradication activity (Paris-1, UK, NW Italy and CSE Europe) and those that had not (Alsace, Paris-2 and Friuli), with a mean loss of MSS of nearly 33\% and a mean loss of $H$ of nearly $21 \%$ in both outbreak categories (Wilcoxon's test performed over loci, $P>0.204$ for both tests).

\section{Discussion}

In this study, we analysed the worldwide genetic variation of the invasive western corn rootworm, Diabrotica virgifera virgifera. We considered almost all known European outbreaks (CSE Europe, NE Italy, NW Italy, the Parisian region and Alsace in France, and the UK), with the exclusion of those whose low density or rapid disappearance, subsequent to eradication attempts made sampling impossible. Moreover, samples collected in the USA and Mexico cover much of the American geographical distribution of WCR. We detected five independent introduction events from the northern USA into Europe (see Fig. 4 for an illustration of the suggested routes of introduction). The diversity loss following these introductions differed considerably between events, suggesting substantial variation in introduction, foundation and/or establishment conditions. Finally, our results indicate that the introduction of WCR into Europe resulted in the redistribution of genetic variance from the intra- to the interpopulational level.

\section{Routes of introduction of WCR}

Our results show a decrease in genetic variability from Mexico to the northeastern USA. This observation is consistent with the hypothesis that WCR originated in the Neotropics (Smith 1966; Branson \& Krysan 1981), subsequently colonizing North America following the expansion of corn cultivation (Krysan et al. 1977).

The routes of WCR introduction in Europe were studied by Miller et al. (2005), using model-based Bayesian approaches to the analysis of genetic variability. Miller et al. (2005) demonstrated that there have been at least three independent introductions of WCR from North America to Europe over the past two decades, leading to the CSE Europe, NW Italy and Paris-1 outbreaks. They also showed that the NE Italian Friuli population corresponded to a secondary introduction from CSE Europe. However, they were unable to draw firm conclusions about the origins of the Paris-2 and Alsace populations. Our analysis supports the conclusions of Miller et al. (2005) concerning the CSE Europe, NE and NW Italy populations, but additional data for the Paris- 1 and 


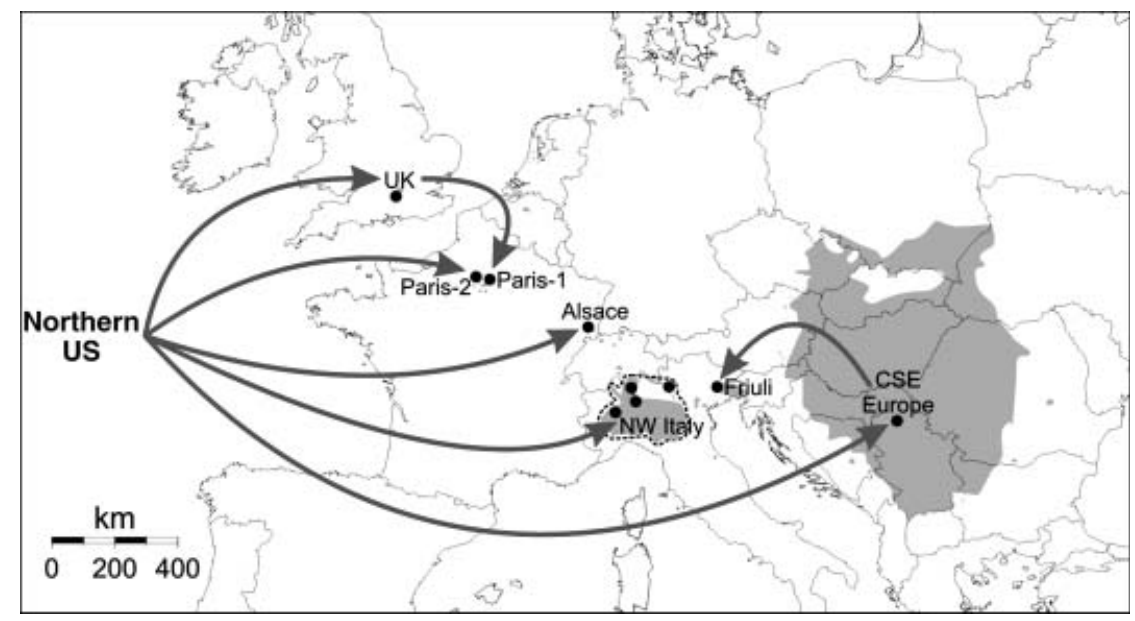

Fig. 4 Suggested routes of introductions of WCR in Europe. The dotted line encircles the NW Italian outbreak.

Alsace populations and analysis of the UK population have provided new information.

The UK outbreak appears to have resulted from a direct introduction of WCR from North America, with the Paris-1 population probably corresponding to a secondary introduction from the UK. The UK population being the source population of the Paris-1 outbreak may initially appear illogical, as WCR was first detected in the Parisian region in 2002 but was not detected in the UK until 1 year later (Kiss et al. 2005a). However, observation dates strongly reflect the effort devoted to WCR monitoring. The first report of WCR in France in 2002 prompted the monitoring of English cornfields, beginning in the summer of 2003 (Cheek et al. 2004; Ostoja-Starzewski 2005) and resulting in the first detection of WCR. In addition, large trap counts at one English site in 2003 indicated that the pest had likely been present for at least 1 year before its detection (Cheek et al. 2004). This information strongly suggests that WCR was present in the UK before 2003 and thus have possibly served as the source of the Paris-1 outbreak. Our data also indicate that the Alsace outbreak, rather than corresponding to a secondary introduction from other European populations, likely originated from a direct introduction from the northern USA. We also found that the Paris-2 population was probably founded by individuals originating from the northern USA. Finally, the weak genetic structure of populations from NW Italy and Switzerland suggested that these populations probably correspond to a single outbreak.

Our results hence indicate that there have been five independent introductions from the northern USA into Europe (Fig. 4) that led to the CSE Europe, NW Italy, the UK, Paris-2 and Alsace populations. Secondary introductions of WCR within Europe were probably responsible for two additional outbreaks: the UK may have been the source of the Paris-1 population and CSE Europe is the most probable source of the Friuli population in NE Italy. The occurrence of multiple introductions of WCR in Europe is consistent with a growing number of analyses of invasive species (e.g. Fonseca et al. 2000; Facon et al. 2003; Kolbe et al. 2004; Chen et al. 2006; Kang et al. 2007), suggesting that multiple introductions of invasive species may be a common phenomenon (reviewed in Bossdorf et al. 2005; Roman \& Darling 2007).

\section{Uncertainty relating to inferences on routes of introduction}

Due to the considerable genetic similarity between the UK and northern USA, it was difficult to firmly exclude UK as the putative source population of the European outbreaks. However, the low but significant level of genetic differentiation between the UK and northern USA populations appears to be sufficient to distinguish between populations assigned to the northern USA and the UK. A careful examination of allelic frequency distributions also revealed the presence of alleles absent from the UK in some European outbreaks. Based on an approximate Bayesian computation (ABC) approach, Miller et al. (2005) rejected the possibility that an unstudied population already established in Europe (such as that the UK outbreak, which was not studied by Miller et al. 2005) was the source of the CSE Europe, Paris-1 and NW Italy outbreaks. Therefore, our analysis as well as that of Miller et al. (2005) suggests that the UK was not the source of most European outbreaks.

Our analysis of the data set presented in this study shows that UK, Paris-2, Alsace, CSE Europe and NW Italy outbreaks were not successive introductions, that is, they did not originate from each other. They thus correspond to independent introductions from their own source population. Strictly, we cannot exclude the possibility that an unstudied population already established in Europe (a 'ghost population') was the origin of these outbreaks. Several lines of evidence refute this latter hypothesis. To be a viable source of new outbreaks, a population would probably need to be 
persistent over time and reasonably large. Detected but unsampled introduced populations (the Netherlands, Belgium and Venice area in Italy) were geographically very limited and did not persist over time (Kiss et al. 2005a). Populations that were not detected by the European monitoring network may have existed. But precisely because they were not detected, these undiscovered outbreaks were probably too small and not sufficiently persistent to be the origin of the studied outbreaks. Moreover, as mentioned previously, Miller et al. (2005) rejected the 'ghost scenario' hypothesis for Paris-1 and 2, Alsace, CSE Europe, and NW Italy. We therefore conclude that five independent introductions of WCR have occurred form northern USA into Europe (Fig. 4).

\section{Heterogeneity in loss of diversity}

Most European outbreaks of WCR (the UK, Alsace, Paris-2, NW Italy and CSE Europe populations) had the same source population (northern USA). This circumstance has provided us with a rare opportunity to analyse multiple instances of the same type of demographical event (i.e. the foundation of new population) within a single species. The history of WCR introduction into Europe thus provides an opportunity to directly compare the effects of independent introductions from the same original gene pool. Our findings show considerable heterogeneity in genetic differentiation between outbreaks and between outbreak and source populations, leading us to reject the hypothesis of homogeneity or repeatability in loss of genetic variability between introductions. The differences in diversity loss were not accounted for by differences in time between the introduction and sampling of populations. The French and Friuli populations were sampled the year they were first detected, but nonetheless differed considerably in terms of loss of diversity compared to their respective sources. Thus, we conclude that the observed variation in the loss of genetic variability may reflect differences in conditions for the introduction, foundation or establishment of populations (e.g. number of founder individuals, number of introductions involved in each outbreak and population dynamics after introduction). Stochastic or deterministic processes, such as eradication attempts, may account for the observed heterogeneity. However, in the particular case of WCR, eradication activity does not seem to be an explanatory factor of the observed heterogeneity in loss of diversity.

Previous population genetic studies of invasive species have reported a wide range of genetic variability loss during introductions (Ross et al. 1996; Tsutsui et al. 2000; Holland 2001; Facon et al. 2003; Johnson \& Starks 2004; Kolbe et al. 2004; Lindholm et al. 2005; Zayed et al. 2007). However, this heterogeneity corresponds to differences in diversity loss between studies focusing on different species (see Cox 2004, Wares et al. 2005, Bossdorf et al. 2005 and Roman \&
Darling 2007 for reviews). In that respect, WCR allowed heterogeneity of diversity loss to be investigated at the intraspecific level (see also Stockwell et al. 1996; Voisin et al. 2005; Kelly et al. 2006; Roman 2006).

Recent reviews have suggested that many successful invasive species suffer no major loss of diversity, suggesting a link between the genetic variation of introduced populations and invasion success. In 29 studies of invasive animals reviewed by Wares et al. (2005), introduced populations were found to contain about $80 \%$ of the native genetic diversity. Similarly, more than $65 \%$ of the invasive species reviewed by Bossdorf et al. (2005) and Roman \& Darling (2007) showed no significant loss of diversity with respect to native populations. For WCR, repeated introductions from the same genetic pool have occurred, making it possible to analyse the link between genetic variation and invasion success within this species. We found that genetic variability within the introduced WCR populations was heterogeneous and that their establishment or invasive success was apparently not related to the level of the genetic variability of the various introduced outbreaks. The extinct Parisian outbreaks and the nonspreading Alsace and UK outbreaks were as diverse as or more diverse than the successfully invasive CSE European and NW Italian outbreaks. This suggests that, at least for invasive pest species subject to human control and eradication, such as WCR, high levels of genetic diversity may not be the key determinant of a successful invasion. However, we measured only evolutionarily neutral genetic variation, through microsatellite markers, and such variation is often weakly correlated with that involved in the adaptive potential of introduced populations in a novel environment (for reviews see Merila \& Crnokrak 2001; Reed \& Frankham 2001; McKay \& Latta 2002). Alternative explanations for the success or failure of WCR invasion may include differences in pest management efforts, such as monitoring and pesticide treatments. The success of the initial European introduction (CSE Europe, first detected in 1992; Kiss et al. 2005a) may in part be due to the absence of monitoring of this species during its early phase of establishment, allowing it to reach high densities before control attempts were implemented.

\section{Redistribution of genetic variance in relation to multiple introductions}

If all the European outbreaks are combined, the genetic variation observed in the invaded area is similar to that found in the northern USA. Thus, recurrent introductions from the same original gene pool resulted in an increase in overall European genetic variability over time, with at least a doubling of allelic diversity within a span of 12 years.

Demonstrations of multiple introductions based on previous population genetics analyses, such as those of Kolbe et al. (2004), Facon et al. (2003) or Genton et al. (2005), have 
mostly shown a redistribution of interpopulation genetic variance into intrapopulation variance (but see Stockwell et al. 1996; Voisin et al. 2005; Kelly et al. 2006). This is of evolutionary importance in terms of adaptation, as natural selection acts on intrapopulation variance (e.g. Falconer \& Mackay 1996). This shift may be accounted for by a single invaded area experiencing multiple introductions from genetically differentiated source populations. The case of WCR is different in that its invasion of Europe has resulted in the redistribution of genetic variance from intrapopulation level to the interpopulation level. Interpopulation variance accounted for $1 \%$ of total variance in the northern USA and $19 \%$ in Europe. The genetic variation contained in a single nonstructured gene pool (northern USA) has been distributed among several introduced, unconnected and genetically differentiated populations over a large area (the European continent).

The lack of examples of a redistribution of genetic variance from the intra- to the interpopulation level during multiple invasions probably results from the technical difficulties associated with the detection of multiple introductions from a single source. The genetic signatures of multiple and single introductions from a single source population are unlikely to be distinguished with commonly used genetic markers (most often mitochondrial markers) and statistical techniques (haplotypic networks or distance-based trees). Moreover, because of the rapid spatial spreading of most invasive populations, a late sampling of the invaded area is likely to result in the detection of a single homogenized and genetically diverse population irrespective of the number of introductions from a unique source population. WCR European outbreaks were detected and sampled at an early stage of the invasion process and hence probably before any secondary contact between outbreaks. This allowed a redistribution of genetic variance from the intra- to the interpopulation levels to be detected, which may actually correspond to a transitory state in the invasion process.

Natural selection acts on intrapopulation variance (e.g. Falconer \& Mackay 1996). The redistribution of genetic variance from the intra- to the interpopulation level in WCR may therefore jeopardize the adaptation of this species to new environmental conditions in Europe. However, geographically close invasive outbreaks, such as those corresponding to the CSE Europe and NW Italy populations, will probably overlap in the future, restoring much of the original intrapopulation genetic variance. It is worth pointing that northern USA populations are polymorphic for adaptive traits, such as insecticide resistance (e.g. Meinke et al. 1998; Parimi et al. 2006) and resistance to crop rotation (Levine et al. 2002). Chemical insecticide treatments and crop rotation strategies are also used in Europe against WCR (Kiss et al. 2005b; Van Rozen \& Ester 2007). Therefore recurrent and independent introductions of WCR into Europe are likely to increase the probability of adaptations to management strategies being introduced, potentially increasing the invasiveness and economic impact of this pest.

\section{Acknowledgements}

We thank Denis Bourguet for assistance in the project, Stefan Toepfer, Lorenzo Furlan, Sylvie Derridj, Gino Angeli, Mario Bertossa, Sharon Cheek and Joe Ostoja-Starzewski for their assistance with sample acquisition and Benoît Facon for critical reading of an earlier version of this manuscript. This work was funded by the French ANR Biodiversité \#ANR-06-BDIV-008-01.

\section{References}

Arnaud-Haond S, Belkhir K (2007) GENCLONE: a computer program to analyse genotypic data, test for clonality and describe spatial clonal organization. Molecular Ecology Notes, 7, 15-17.

Ayala FJ, Serra L, Prevosti A (1989) A grand experiment in evolution: the Drosophila subobscura colonization of the Americas. Genome, 31, 246-255.

Bossdorf O, Auge H, Lafuma L et al. (2005) Phenotypic and genetic differentiation between native and introduced plant populations. Oecologia, 144, 1-11.

Branson TF, Krysan JL (1981) Feeding and oviposition behavior and life cycle strategies of Diabrotica: an evolutionary view with implications for pest management. Environmental Entomology, 10, 826-831.

Cadotte MW, McMahon SM, Fukami T (2006) Conceptual Ecology and Invasion Biology: Reciprocal Approaches to Nature. Springer, Dordrecht, The Netherlands.

Cheek S, Baker RHA, Cannon RJC et al. (2004) First findings of the western corn rootworm Diabrotica virgifera virgifera in the UK. IWGO Newsletter, 25, 21-22.

Chen YH, Opp SB, Berlocher SH, Roderick GK (2006) Are bottlenecks associated with colonization? Genetic diversity and diapause variation of native and introduced Rhagoletis completa populations. Oecologia, 149, 656-667.

Cox GW (2004) Founder effects and exotic variability. In: Alien Species and Evolution: The Evolutionary Ecology of Exotic Plants, Animals, Microbes, and Interacting Native Species (ed. Cox GW), pp. 32-46. Island Press, Washington.

Dlugosch KM, Parker IM (2008) Founding events in species invasions: genetic variation, adaptive evolution, and the role of multiple introductions. Molecular Ecology, 17, 431-449.

Estoup A, Largiadèr CR, Perrot E, Chourrout D (1996) Rapid onetube extraction for reliable PCR detection of fish polymorphic markers and transgenes. Molecular Marine Biology and Biotechnology, 5, 295-298.

Facon B, Pointier J-P, Glaubrecht M et al. (2003) A molecular phylogeography approach to biological invasions of the New World by parthenogenetic Thiarid snails. Molecular Ecology, 12, 3027-3039.

Falconer DS, Mackay TF (1996) Introduction to Quantitative Genetics. 4th edn. Addison-Wesley Longman Limited, Harlow, UK.

Fonseca DM, LaPointe DA, Fleischer RC (2000) Bottlenecks and multiple introductions: population genetics of the vector of avian malaria in Hawaii. Molecular Ecology, 9, 1803-1814.

Genton BJ, Shykoff JA, Giraud T (2005) High genetic diversity in French invasive populations of common ragweed, Ambrosia 
artemisiifolia, as a result of multiple sources of introduction. Molecular Ecology, 14, 4275-4285.

Grevstad FS (1999) Experimental invasions using biological control introductions: the influence of release size on the chance of population establishment. Biological Invasions, 1, 313-323.

Holland BS (2001) Invasion without a bottleneck: microsatellite variation in natural and invasive populations of the brown mussel Perna perna (L.). Marine Biotechnology, 3, 407-415.

Johnson RN, Starks PT (2004) A surprising level of genetic diversity in an invasive wasp: Polistes dominulus in the northeastern United States. Annals of the Entomological Society of America, 97, 732-737.

Kang M, Buckley YM, Lowe AJ (2007) Testing the role of genetic factors across multiple independent invasions of the shrub Scotch broom (Cytisus scoparius). Molecular Ecology, 16, 46624673.

Kelly DW, Muirhead JR, Heath DD, Macisaac HJ (2006) Contrasting patterns in genetic diversity following multiple invasions of fresh and brackish waters. Molecular Ecology, 15, 3641-3653.

Kim KS, Sappington TW (2005a) Genetic structuring of western corn rootworm (Coleoptera: Chrysomelidae) populations in the United States based on microsatellite loci analysis. Environmental Entomology, 34, 494-503.

Kim KS, Sappington TW (2005b) Polymorphic microsatellite loci from the western corn rootworm (Insecta: Coleoptera: Chrysomelidae) and cross-amplification with other Diabrotica spp. Molecular Ecology Notes, 5, 115-117.

Kim KS, Stolz U, Miller NJ et al. (2008) A core set of microsatellite markers for Western corn rootworm (Coleoptera: Chrysomelidae) population genetics studies. Environmental Entomology, 37, $293-$ 300.

Kiss J, Edwards CR, Berger HK et al. (2005a) Monitoring of western corn rootworm (Diabrotica virgifera virgifera LeConte) in Europe 1992-2003. In: Western Corn Rootworm: Ecology and Management (eds Vidal S, Kuhlmann U, Edwards CR), pp. 29-39. CABI Publishing, Wallingford, UK.

Kiss J, Komaromi J, Bayar K, Edwards CR, Hatala-Zseller I (2005b) Western corn rootworm (Diabrotica virgifera virgifera LeConte) and the crop rotation systems in Europe. In: Western Corn Rootworm: Ecology and Management (eds Vidal S, Kuhlmann U, Edwards CR), pp. 189-220. CABI Publishing, Wallingford, UK.

Kolbe JJ, Glor RE, Schettino LRG et al. (2004) Genetic variation increases during biological invasion by a Cuban lizard. Nature, 431, 177-181.

Krysan JL, Smith RF (1987) Systematics of the virgifera species group of Diabrotica (Coleoptera: Chrysomelidae: Galerucinae). Entomography, 5, 375-484.

Krysan JL, Branson TF, Diaz Castro G (1977) Diapause in Diabrotica virgifera virgifera (Coleoptera: Chrysomelidae): a comparison of eggs from temperate and subtropical climates. Entomologia Experimentalis et Applicata, 22, 81-89.

Leberg PL (2002) Estimating allelic richness: effects of sample size and bottlenecks. Molecular Ecology, 11, 2445-2449.

Levine E, Spencer JL, Isard SA, Onstad DW, Gray ME (2002) Adaptation of the western corn rootworm to crop rotation: evolution of a new strain in response to a management practice. American Entomologist, 48, 94-107.

Lindholm AK, Breden F, Alexander HJ et al. (2005) Invasion success and genetic diversity of introduced populations of guppies Poecilia reticulata in Australia. Molecular Ecology, 14, 3671-3682.
Lockwood JL, Cassey P, Blackburn T (2005) The role of propagule pressure in explaining species invasions. Trends in Ecology $\mathcal{E}$ Evolution, 20, 223-228.

McKay JK, Latta RG (2002) Adaptive population divergence: markers, QTL and traits. Trends in Ecology \& Evolution, 17, 285291.

McKinney ML, Lockwood JL (1999) Biotic homogenization: a few winners replacing many losers in the next mass extinction. Trends in Ecology \& Evolution, 14, 450-453.

Meinke LJ, Siegfried BD, Wright RJ, Chandler LD (1998) Adult susceptibility of Nebraska western corn rootworm (Coleoptera: Chrysomelidae) populations to selected insecticides. Journal of Economic Entomology, 91, 594-600.

Merila J, Crnokrak P (2001) Comparison of genetic differentiation at marker loci and quantitative traits. Journal of Evolutionary Biology, 14, 892-903.

Metcalf RL (1983) Implications and prognosis of resistance to insecticides. In: Pest Resistance to Pesticides (eds Georghio GP, Saito T), pp. 703-733. Plenum, New York.

Miller NJ, Ciosi M, Sappington TW et al. (2007) Genome scan of Diabrotica virgifera virgifera for genetic variation associated with crop rotation tolerance. Journal of Applied Entomology, 131, 378385.

Miller N, Estoup A, Toepfer S et al. (2005) Multiple transatlantic introductions of the western corn rootworm. Science, 310, 992992.

Nei M (1987) Molecular Evolutionary Genetics. Columbia University Press, New York.

Novak SJ, Mack RN (2005) Genetic bottelenecks in alien plant species. In: Species Invasions: Insights into Ecology, Evolution and Biogeography (eds Sax DF, Stachowicz JJ, Gaines SD), pp. 201228. Sinauer \& Associates Inc, Sunderland, Massachusetts.

Olden JD, LeRoy Poff N, Douglas MR, Douglas ME, Fausch KD (2004) Ecological and evolutionary consequences of biotic homogenization. Trends in Ecology \& Evolution, 19, 18-24.

Ostoja-Starzewski JC (2005) The western corn rootworm Diabrotica virgifera virgifera Le Conte (Col., Chrysomelidae) in Britain: distribution, description and biology. Entomologist's Monthly Magazine, 141, 175-182.

Paetkau D, Slade R, Burden M, Estoup A (2004) Genetic assignment methods for the direct, real-time estimation of migration rate: a simulation-based exploration of accuracy and power. Molecular Ecology, 13, 55-65.

Parimi S, Meinke LJ, French BW, Chandler LD, Siegfried BD (2006) Stability and persistence of aldrin and methyl-parathion resistance in western corn rootworm populations (Coleoptera: Chrysomelidae). Crop Protection, 25, 269-274.

Pascual M, Chapuis MP, Mestres F et al. (2007) Introduction history of Drosophila subobscura in the New World: a microsatellitebased survey using ABC methods. Molecular Ecology, 16, 30693083.

Pimentel D, McNair S, Janecka J et al. (2001) Economic and environmental threats of alien plant, animal, and microbe invasions. Agriculture, Ecosystems and Environment, 84, 1-20.

Piry S, Alapetite A, Cornuet JM et al. (2004) GENECLAss 2: a software for genetic assignment and first-generation migrant detection. Journal of Heredity, 95, 536-539.

Rannala B, Mountain JL (1997) Detecting immigration by using multilocus genotypes. Proceedings of the National Academy of Sciences, USA, 94, 9197-9201.

Raymond M, Rousset F (1995a) An exact test for population differentiation. Evolution, 49, 1280-1283. 
Raymond M, Rousset F (1995b) GENEPOP (version. 1.2): a population genetics software for exact tests and ecumenicism. Journal of Heredity, 86, 248-249.

Reed DH, Frankham R (2001) How closely correlated are molecular and quantitative measures of genetic variation? A meta-analysis. Evolution, 55, 1095-1103.

Reznick DN, Ghalambor CK (2001) The population ecology of contemporary adaptations: what empirical studies reveal about the conditions that promote adaptive evolution. Genetica, 112, 183-198.

Roman J (2006) Diluting the founder effect: cryptic invasions expand a marine invader's range. Proceedings of the Royal Society B: Biological Sciences, 273, 2453-2459.

Roman J, Darling JA (2007) Paradox lost: genetic diversity and the success of aquatic invasions. Trends in Ecology \& Evolution, 22, 454-464.

Ross KG, Vargo EL, Keller L (1996) Social evolution in a new environment: the case of introduced fire ants. Proceedings of the National Academy of Sciences, USA, 93, 3021-3025.

Ruiz GM, Rawlings TK, Dobbs FC et al. (2000) Global spread of microorganisms by ships: ballast water discharged from vessels harbours a cocktail of potential pathogens. Nature, 408, 49-50.

Sax DF, Stachowicz JJ, Gaines SD (2005) Species Invasions: Insights into Ecology, Evolution, and Biogeography. Sinauer \& Associates, Sunderland, Massachusetts.

Schierenbeck KA, Aïnouche ML (2006) The role of evolutionary genetics in studies of plant invasions. In: Conceptual Ecology and Invasion Biology: Reciprocal Approaches to Nature (eds Cadotte MW, McMahon SM, Fukami T), pp. 193-221. Springer, Dordrecht, The Netherlands.

Smith RF (1966) Distributional patterns of selected western North American insects: the distribution of diabroticites in western North America. Bulletin of Entomological Society of America, 12, $108-110$.

Sokal RR, Rolf FJ (1995) Biometry: The Principles and Practice of Statistics in Biology Research. 3rd edn. W.H. Freeman, New York.

Spencer JL, Levine E, Isard SA, Mabry TR (2005) Movement, dispersal and behaviour of western corn rootworm adults in rotated maize and soybean fields. In: Western Corn Rootworm: Ecology and Management (eds Vidal S, Kuhlmann U, Edwards CR), pp. 121-144. CABI Publishing, Wallingford, UK.

Stockwell CA, Mulvey M, Vinyard GL (1996) Translocations and the preservation of allelic diversity. Conservation Biology, 10, 1133-1141.

Sunnucks P, Hales DF (1996) Numerous transposed sequences of mitochondrial cytochrome oxidase I-II in aphids of the genus Sitobion (Hemiptera: Aphididae). Molecular Biology and Evolution, 13, 510-524.

Tsutsui ND, Suarez AV, Holway DA, Case TJ (2000) Reduced genetic variation and the success of an invasive species. Proceedings of the National Academy of Sciences, USA, 97, 5948-5953.

Van Rozen K, Ester A (2007) Chemical control against Diabrotica v. virgifera Le Conte: a review of the historical and current pest control strategies. IWGO Newsletter, 28, 7-11.

Voisin M, Engel CR, Viard F (2005) Differential shuffling of native genetic diversity across introduced regions in a brown alga: aquaculture vs. maritime traffic effects. Proceedings of the National Academy of Sciences, USA, 102, 5432-5437.

Wares JP, Hughes AR, RK G (2005) Mechanisms that drive evolutionary change: insights from species introductions and invasions. In: Species Invasions: Insights into Ecology, Evolution and Biogeography (eds Sax DF, Stachowicz JJ, Gaines SD), pp. 229-257. Sinauer \& Associates Inc, Sunderland, Massachusetts.

Weir BS, Cockerham C (1984) Estimating F-statistics for the analysis of population structure. Evolution, 38, 1358-1370.

Zayed A, Constantin SA, Packer L (2007) Successful biological invasion despite a severe genetic load. PLoS ONE, 2, e868.

This study is part of Marc Ciosi's PhD thesis which aimed at describing routes of introduction of the western corn rootworm into Europe as well as describing founder effects for each introduction event identified. N. J. Miller and K. S. Kim are interested in the genetics of pest insects mainly to understand range expansions of such organisms and to identify genetic markers linked to the resistance of those insects to management strategies. R. Giordano's research focuses on exploring the phylogeography of Diabrotica virgifera using mitochondria and Wolbachia genes. A. Estoup and T. Guillemaud's research focuses mainly on the evolutionary biology of invading species and they are currently interested in the application of methods for historical inferences using molecular markers in the context of biological invasions.

\section{Supplementary material}

The following supplementary material is available for this article:

Table S1 Allele frequency distributions of the WCR samples collected in North America and in Europe. The Lombardy and SW samples were considered as a single population sample (denoted Lombardy-SW), as they displayed no significant genetic differentiation

This material is available as part of the online article from: http:/ / www.blackwell-synergy.com/doi/abs/10.1111/ j.1365-294X.2008.03866.x

(This link will take you to the article abstract).

Please note: Blackwell Publishing are not responsible for the content or functionality of any supplementary materials supplied by the authors. Any queries (other than missing material) should be directed to the corresponding author for the article. 


\section{Supplementary material}

Table S: Allele frequency distributions of the WCR samples collected in North America and in Europe. The Lombardy and SW samples were considered as a single population sample (denoted Lombardy-SW), as they displayed no significant genetic differentiation.

\begin{tabular}{|c|c|c|c|c|c|c|c|c|c|c|c|c|c|c|c|}
\hline & \multirow[b]{2}{*}{ Allele } & \multicolumn{5}{|c|}{ North America } & \multicolumn{9}{|c|}{ Europe } \\
\hline & & Mexico & Arizona & Texas & Illinois & Pennsylvania & $\begin{array}{c}\text { CSE } \\
\text { Europe }\end{array}$ & Friuli & Trentino & $\begin{array}{c}\text { Lombardy- } \\
\text { SW }\end{array}$ & Piedmont & Paris-1 & Paris-2 & Alsace & UK \\
\hline \multicolumn{16}{|l|}{ Locus DVV-D2 } \\
\hline Gene number & & 28 & 76 & 102 & 120 & 124 & 70 & 52 & 86 & 176 & 80 & 38 & 144 & 18 & 68 \\
\hline \multirow[t]{17}{*}{ Allele number } & & 7 & 11 & 8 & 8 & 9 & 4 & 3 & 2 & 3 & 4 & 6 & 4 & 6 & 9 \\
\hline & 177 & 0.214 & 0.053 & 0 & 0 & 0 & 0 & 0 & 0 & 0 & 0 & 0.026 & 0 & 0.056 & 0.015 \\
\hline & 179 & 0.143 & 0.039 & 0.118 & 0 & 0 & 0 & 0 & 0 & 0 & 0 & 0 & 0 & 0 & 0 \\
\hline & 181 & 0.357 & 0.395 & 0.225 & 0.350 & 0.218 & 0.214 & 0.558 & 0 & 0 & 0.100 & 0.421 & 0.083 & 0.611 & 0.206 \\
\hline & 183 & 0.071 & 0.382 & 0.392 & 0.367 & 0.548 & 0.329 & 0.058 & 0.802 & 0.750 & 0.663 & 0.316 & 0.681 & 0.111 & 0.412 \\
\hline & 185 & 0.143 & 0.026 & 0 & 0 & 0 & 0 & 0 & 0 & 0 & 0 & 0 & 0 & 0 & 0 \\
\hline & 187 & 0 & 0 & 0.029 & 0.050 & 0.024 & 0.100 & 0 & 0 & 0 & 0 & 0 & 0 & 0.111 & 0.147 \\
\hline & 189 & 0.036 & 0 & 0 & 0.017 & 0.008 & 0 & 0 & 0 & 0 & 0 & 0 & 0 & 0.056 & 0.015 \\
\hline & 191 & 0 & 0.013 & 0 & 0 & 0 & 0 & 0 & 0 & 0 & 0 & 0 & 0 & 0 & 0 \\
\hline & 193 & 0 & 0.026 & 0 & 0 & 0 & 0 & 0 & 0 & 0 & 0 & 0 & 0 & 0 & 0 \\
\hline & 197 & 0 & 0.026 & 0 & 0 & 0 & 0 & 0 & 0 & 0.006 & 0 & 0 & 0 & 0 & 0 \\
\hline & 199 & 0 & 0.013 & 0.029 & 0.033 & 0.024 & 0 & 0 & 0.198 & 0.244 & 0.188 & 0 & 0.056 & 0 & 0.044 \\
\hline & 201 & 0 & 0 & 0.137 & 0.067 & 0.097 & 0.357 & 0.385 & 0 & 0 & 0 & 0.026 & 0.181 & 0.056 & 0.029 \\
\hline & 203 & 0 & 0.013 & 0.010 & 0.025 & 0.048 & 0 & 0 & 0 & 0 & 0.050 & 0.158 & 0 & 0 & 0.088 \\
\hline & 205 & 0 & 0.013 & 0.059 & 0.092 & 0.024 & 0 & 0 & 0 & 0 & 0 & 0 & 0 & 0 & 0.044 \\
\hline & 207 & 0 & 0 & 0 & 0 & 0.008 & 0 & 0 & 0 & 0 & 0 & 0.053 & 0 & 0 & 0 \\
\hline & 217 & 0.036 & 0 & 0 & 0 & 0 & 0 & 0 & 0 & 0 & 0 & 0 & 0 & 0 & 0 \\
\hline \multicolumn{16}{|l|}{ Locus DVV-D4 } \\
\hline Gene number & & 28 & 76 & 102 & 120 & 124 & 70 & 52 & 84 & 176 & 80 & 38 & 134 & 18 & 66 \\
\hline Allele number & & 6 & 8 & 6 & 8 & 7 & 3 & 2 & 3 & 2 & 4 & 4 & 4 & 5 & 7 \\
\hline & 219 & 0.536 & 0.132 & 0.098 & 0.175 & 0.210 & 0 & 0 & 0.012 & 0 & 0.013 & 0 & 0.030 & 0.111 & 0.152 \\
\hline & 223 & 0 & 0 & 0.118 & 0.125 & 0.169 & 0.286 & 0.288 & 0 & 0 & 0 & 0.105 & 0.157 & 0.056 & 0.167 \\
\hline & 225 & 0.036 & 0.197 & 0.510 & 0.442 & 0.452 & 0.643 & 0.712 & 0.750 & 0.739 & 0.775 & 0.342 & 0.761 & 0.333 & 0.394 \\
\hline & 227 & 0.107 & 0.026 & 0.059 & 0.075 & 0.048 & 0 & 0 & 0 & 0 & 0.013 & 0.289 & 0 & 0.111 & 0.152 \\
\hline & 229 & 0.071 & 0.026 & 0 & 0 & 0 & 0 & 0 & 0 & 0 & 0 & 0 & 0 & 0 & 0 \\
\hline
\end{tabular}




\begin{tabular}{|c|c|c|c|c|c|c|c|c|c|c|c|c|c|c|}
\hline 231 & 0.143 & 0.118 & 0.049 & 0.100 & 0.065 & 0.071 & 0 & 0.238 & 0.261 & 0.200 & 0.263 & 0.052 & 0.389 & 0.061 \\
\hline 233 & 0 & 0.382 & 0.167 & 0.042 & 0.032 & 0 & 0 & 0 & 0 & 0 & 0 & 0 & 0 & 0.061 \\
\hline 235 & 0.107 & 0.105 & 0 & 0.017 & 0 & 0 & 0 & 0 & 0 & 0 & 0 & 0 & 0 & 0 \\
\hline 237 & 0 & 0 & 0 & 0.025 & 0.024 & 0 & 0 & 0 & 0 & 0 & 0 & 0 & 0 & 0.015 \\
\hline 239 & 0 & 0.013 & 0 & 0 & 0 & 0 & 0 & 0 & 0 & 0 & 0 & 0 & 0 & 0 \\
\hline
\end{tabular}

Locus DVV-D5

Gene number

Allele number

$\begin{array}{llllll} & 26 & 80 & 102 & 120 & 124 \\ & 5 & 4 & 4 & 3 & 2 \\ 162 & 0.038 & 0 & 0 & 0 & 0 \\ 168 & 0 & 0 & 0.039 & 0 & 0 \\ 170 & 0.077 & 0.013 & 0 & 0 & 0 \\ 172 & 0.692 & 0.863 & 0.843 & 0.867 & 0.790 \\ 174 & 0.154 & 0.100 & 0.029 & 0.025 & 0 \\ 176 & 0.038 & 0.025 & 0.088 & 0.108 & 0.210\end{array}$

Locus DVV-D8

Gene number

Allele number

$\begin{array}{llllll} & 24 & 80 & 102 & 120 & 124 \\ & 14 & 18 & 18 & 17 & 17 \\ 208 & 0 & 0.013 & 0 & 0 & 0 \\ 212 & 0.042 & 0.063 & 0.029 & 0.092 & 0.040 \\ 214 & 0.125 & 0.150 & 0 & 0.008 & 0 \\ 216 & 0.083 & 0.088 & 0.127 & 0.033 & 0.145 \\ 218 & 0.042 & 0.050 & 0.098 & 0.383 & 0.234 \\ 220 & 0 & 0.150 & 0.069 & 0.058 & 0.065 \\ 222 & 0.125 & 0.013 & 0.088 & 0.033 & 0.040 \\ 224 & 0.042 & 0.038 & 0.059 & 0.033 & 0.024 \\ 226 & 0 & 0.038 & 0.039 & 0.025 & 0.024 \\ 228 & 0.042 & 0.100 & 0.010 & 0 & 0 \\ 230 & 0.042 & 0.113 & 0.127 & 0.008 & 0 \\ 232 & 0.083 & 0.038 & 0.039 & 0.025 & 0.016 \\ 234 & 0.125 & 0.025 & 0.029 & 0.008 & 0.016 \\ 236 & 0.042 & 0.025 & 0.049 & 0 & 0.016 \\ 238 & 0.042 & 0.050 & 0.020 & 0.008 & 0 \\ 240 & 0.125 & 0 & 0.069 & 0.050 & 0.081 \\ 242 & 0.042 & 0 & 0.029 & 0.083 & 0.056 \\ 244 & 0 & 0 & 0.039 & 0.083 & 0.121\end{array}$

74
1
0
0
0
1.000
0
0

$\begin{array}{lll}34 & 82 & 172 \\ 1 & 1 & 1 \\ 0 & 0 & 0 \\ 0 & 0 & 0 \\ 0 & 0 & 0 \\ 1.000 & 1.000 & 1.000 \\ 0 & 0 & 0 \\ 0 & 0 & 0\end{array}$

80
1
0
0
0
1.000
0
0

38
2
0
0
0
0.632
0
0.368

128
2
0
0
0
0.852
0
0.148

$\begin{array}{ll}18 & 72 \\ 2 & 2 \\ 0 & 0 \\ 0 & 0 \\ 0 & 0 \\ 0.944 & 0.889 \\ 0 & 0 \\ 0.056 & 0.111\end{array}$

74
5
0
0
0
0
0.135
0
0
0
0
0
0
0
0
0
0
0
0.108
0.595

34
2
0
0
0
0
0
0
0
0
0
0
0
0
0
0
0
0
0
0.706

$\begin{array}{ll}84 & 172 \\ 7 & 9 \\ 0 & 0 \\ 0 & 0 \\ 0 & 0 \\ 0.071 & 0.128 \\ 0.071 & 0.006 \\ 0.012 & 0 \\ 0.036 & 0.070 \\ 0.298 & 0.297 \\ 0 & 0 \\ 0 & 0 \\ 0 & 0 \\ 0 & 0 \\ 0 & 0 \\ 0 & 0 \\ 0 & 0 \\ 0.155 & 0.233 \\ 0 & 0.006 \\ 0 & 0\end{array}$

80
10
0.013
0
0
0.138
0.150
0.013
0.013
0.225
0
0
0
0
0.013
0
0
0.175
0
0.050

38
5
0
0
0
0.079
0.763
0.053
0
0
0
0
0
0
0
0
0
0
0.053
0.053

126
6
0
0
0.056
0.302
0.516
0
0.016
0.056
0
0
0
0
0
0
0
0
0
0

$\begin{array}{ll}18 & 72 \\ 8 & 12 \\ 0 & 0 \\ 0.111 & 0.056 \\ 0 & 0 \\ 0.111 & 0.042 \\ 0.278 & 0.375 \\ 0.167 & 0.028 \\ 0.056 & 0.125 \\ 0 & 0.069 \\ 0 & 0.014 \\ 0 & 0 \\ 0 & 0 \\ 0 & 0 \\ 0 & 0 \\ 0 & 0 \\ 0 & 0 \\ 0 & 0.083 \\ 0.056 & 0.111 \\ 0.167 & 0.056\end{array}$




$\begin{array}{lllllllllllllll}246 & 0 & 0 & 0.049 & 0.017 & 0.065 & 0.149 & 0.294 & 0 & 0.006 & 0 & 0 & 0 & 0.056 & 0.028 \\ 248 & 0 & 0 & 0.029 & 0.050 & 0.032 & 0.014 & 0 & 0.357 & 0.250 & 0.213 & 0 & 0.056 & 0 & 0.014 \\ 250 & 0 & 0.013 & 0 & 0 & 0.016 & 0 & 0 & 0 & 0.006 & 0 & 0 & 0 & 0 & 0 \\ 252 & 0 & 0.025 & 0 & 0 & 0.008 & 0 & 0 & 0 & 0 & 0 & 0 \\ 256 & 0 & 0.013 & 0 & 0 & 0 & 0 & 0 & 0 & 0 & 0 & 0 & 0 & 0 & 0\end{array}$

Locus DVV-D9

Gene number

$\begin{array}{llllll} & 24 & 80 & 102 & 120 & 124 \\ & 5 & 5 & 6 & 3 & 6 \\ 128 & 0 & 0 & 0.020 & 0 & 0.008 \\ 130 & 0.208 & 0.063 & 0 & 0 & 0 \\ 136 & 0 & 0 & 0.010 & 0 & 0 \\ 138 & 0.292 & 0.313 & 0.294 & 0.292 & 0.250 \\ 140 & 0.292 & 0.450 & 0.569 & 0.567 & 0.597 \\ 142 & 0.125 & 0.138 & 0.088 & 0 & 0.024 \\ 150 & 0.083 & 0.038 & 0.020 & 0.142 & 0.105 \\ 152 & 0 & 0 & 0 & 0 & 0.016\end{array}$

70
2
0
0
0
0.100
0.900
0
0
0

$\begin{array}{lll}52 & 84 & 172 \\ 1 & 3 & 2 \\ 0 & 0 & 0 \\ 0 & 0 & 0 \\ 0 & 0 & 0 \\ 0 & 0.464 & 0.378 \\ 1.000 & 0.524 & 0.622 \\ 0 & 0 & 0 \\ 0 & 0.012 & 0 \\ 0 & 0 & 0\end{array}$

80
2
0
0
0
0.250
0.750
0
0
0

$\begin{array}{llll}38 & 144 & 18 & 72 \\ 2 & 3 & 3 & 2 \\ 0 & 0 & 0 & 0 \\ 0 & 0 & 0 & 0 \\ 0 & 0 & 0 & 0 \\ 0.421 & 0.299 & 0.111 & 0.347 \\ 0.579 & 0.438 & 0.778 & 0.653 \\ 0 & 0 & 0 & 0 \\ 0 & 0 & 0.111 & 0 \\ 0 & 0.264 & 0 & 0\end{array}$

Locus DVV-D11

Gene number

Allele number

$\begin{array}{llllll} & 28 & 76 & 102 & 120 & 124 \\ & 12 & 14 & 12 & 12 & 12 \\ 174 & 0.107 & 0.026 & 0 & 0 & 0 \\ 176 & 0.179 & 0.487 & 0.353 & 0.383 & 0.298 \\ 178 & 0.036 & 0 & 0.029 & 0.017 & 0.105 \\ 180 & 0.071 & 0.053 & 0 & 0 & 0 \\ 182 & 0.107 & 0.092 & 0.108 & 0.050 & 0.065 \\ 184 & 0.036 & 0.026 & 0 & 0 & 0 \\ 188 & 0.071 & 0 & 0 & 0 & 0 \\ 190 & 0 & 0.013 & 0 & 0 & 0 \\ 192 & 0.071 & 0 & 0 & 0 & 0 \\ 196 & 0.036 & 0 & 0.059 & 0.083 & 0.169 \\ 198 & 0.143 & 0.079 & 0.118 & 0.025 & 0.008 \\ 200 & 0.107 & 0.053 & 0.147 & 0.117 & 0.073 \\ 202 & 0 & 0.026 & 0.078 & 0.108 & 0.048 \\ 204 & 0.036 & 0 & 0.010 & 0.008 & 0.008 \\ 206 & 0 & 0.013 & 0.029 & 0.158 & 0.194 \\ 208 & 0 & 0 & 0 & 0.017 & 0.008\end{array}$

$\begin{array}{lllllllll}56 & 50 & 84 & 176 & 78 & 38 & 82 & 18 & 66 \\ 6 & 2 & 4 & 6 & 8 & 6 & 6 & 6 & 8 \\ 0 & 0 & 0 & 0 & 0 & 0 & 0 & 0 & 0 \\ 0.339 & 0 & 0 & 0 & 0.077 & 0.737 & 0.280 & 0.389 & 0.348 \\ 0.268 & 0 & 0.274 & 0.381 & 0.218 & 0.026 & 0 & 0 & 0.106 \\ 0 & 0 & 0 & 0 & 0 & 0 & 0 & 0 & 0 \\ 0 & 0 & 0 & 0 & 0.064 & 0.026 & 0.012 & 0.056 & 0.076 \\ 0 & 0 & 0 & 0 & 0 & 0 & 0 & 0 & 0 \\ 0 & 0 & 0 & 0 & 0 & 0 & 0 & 0 & 0 \\ 0 & 0 & 0 & 0 & 0 & 0 & 0 & 0 & 0 \\ 0 & 0 & 0 & 0 & 0 & 0 & 0 & 0 & 0 \\ 0.214 & 0.560 & 0.310 & 0.307 & 0.333 & 0.026 & 0.159 & 0.056 & 0.045 \\ 0 & 0 & 0 & 0.006 & 0.013 & 0 & 0.244 & 0 & 0 \\ 0 & 0 & 0.226 & 0.148 & 0.115 & 0.132 & 0 & 0.222 & 0.136 \\ 0 & 0 & 0 & 0.011 & 0.064 & 0.053 & 0 & 0.222 & 0.167 \\ 0 & 0 & 0 & 0 & 0 & 0 & 0 & 0.056 & 0 \\ 0.125 & 0.440 & 0.190 & 0.148 & 0.115 & 0 & 0.280 & 0 & 0.091 \\ 0.018 & 0 & 0 & 0 & 0 & 0 & 0 & 0 & 0\end{array}$




\begin{tabular}{|c|c|c|c|c|c|c|c|c|c|c|c|c|c|c|}
\hline 210 & 0 & 0.039 & 0 & 0 & 0.008 & 0 & 0 & 0 & 0 & 0 & 0 & 0 & 0 & 0 \\
\hline 212 & 0 & 0.039 & 0.039 & 0.017 & 0 & 0.036 & 0 & 0 & 0 & 0 & 0 & 0.024 & 0 & 0.030 \\
\hline 214 & 0 & 0 & 0.020 & 0.017 & 0.016 & 0 & 0 & 0 & 0 & 0 & 0 & 0 & 0 & 0 \\
\hline 216 & 0 & 0 & 0.010 & 0 & 0 & 0 & 0 & 0 & 0 & 0 & 0 & 0 & 0 & 0 \\
\hline 232 & 0 & 0.013 & 0 & 0 & 0 & 0 & 0 & 0 & 0 & 0 & 0 & 0 & 0 & 0 \\
\hline
\end{tabular}

Locus DVV-T2

Gene number

$\begin{array}{llllll} & 28 & 76 & 102 & 120 & 124 \\ & 5 & 6 & 6 & 3 & 3 \\ 204 & 0.214 & 0.053 & 0.088 & 0 & 0 \\ 210 & 0 & 0.132 & 0.245 & 0.317 & 0.298 \\ 213 & 0.036 & 0 & 0 & 0 & 0 \\ 216 & 0.036 & 0.013 & 0.010 & 0 & 0 \\ 219 & 0.143 & 0.145 & 0.078 & 0.150 & 0.089 \\ 222 & 0.571 & 0.592 & 0.569 & 0.533 & 0.613 \\ 225 & 0 & 0.066 & 0 & 0 & 0 \\ 240 & 0 & 0 & 0.010 & 0 & 0\end{array}$

70
2
0
0.100
0
0
0
0.900
0
0

$\begin{array}{lll}52 & 86 & 176 \\ 1 & 1 & 1 \\ 0 & 0 & 0 \\ 0 & 0 & 0 \\ 0 & 0 & 0 \\ 0 & 0 & 0 \\ 0 & 0 & 0 \\ 1.000 & 1.000 & 1.000 \\ 0 & 0 & 0 \\ 0 & 0 & 0\end{array}$

80
3
0
0.075
0
0
0.100
0.825
0
0

$\begin{array}{llll}38 & 144 & 18 & 68 \\ 2 & 2 & 3 & 3 \\ 0 & 0 & 0 & 0 \\ 0.447 & 0.313 & 0.167 & 0.206 \\ 0 & 0 & 0 & 0 \\ 0 & 0 & 0 & 0 \\ 0 & 0 & 0.111 & 0.176 \\ 0.553 & 0.688 & 0.722 & 0.618 \\ 0 & 0 & 0 & 0 \\ 0 & 0 & 0 & 0\end{array}$

Locus DVV-ET1

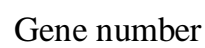

$\begin{array}{llllll} & 22 & 80 & 102 & 120 & 124 \\ & 4 & 6 & 5 & 4 & 4 \\ 160 & 0 & 0.300 & 0.422 & 0.450 & 0.540 \\ 163 & 0.364 & 0.250 & 0.284 & 0.283 & 0.202 \\ 166 & 0.318 & 0.075 & 0.147 & 0.192 & 0.194 \\ 169 & 0.273 & 0.300 & 0.127 & 0.075 & 0.065 \\ 172 & 0 & 0.050 & 0.020 & 0 & 0 \\ 178 & 0.045 & 0.025 & 0 & 0 & 0\end{array}$

64
4
0.234
0.234
0.484
0.047
0
0

$\begin{array}{lll}32 & 82 & 172 \\ 2 & 2 & 2 \\ 0 & 0.915 & 0.983 \\ 0 & 0.085 & 0.017 \\ 0.688 & 0 & 0 \\ 0.313 & 0 & 0 \\ 0 & 0 & 0 \\ 0 & 0 & 0\end{array}$

80
2
0.925
0.075
0
0
0
0

$\begin{array}{llll}38 & 128 & 18 & 72 \\ 3 & 3 & 4 & 3 \\ 0.842 & 0.422 & 0.556 & 0.653 \\ 0.132 & 0.164 & 0.111 & 0.250 \\ 0.026 & 0.414 & 0.278 & 0.097 \\ 0 & 0 & 0.056 & 0 \\ 0 & 0 & 0 & 0 \\ 0 & 0 & 0 & 0\end{array}$

